\title{
Frequency of Obstructed Labor in Teenage Pregnancy
}

\author{
Shaikh S, ${ }^{1}$ Shaikh AH, ${ }^{2}$ Shaikh SAH, ${ }^{3}$ Isran B ${ }^{4}$ \\ ${ }^{1}$ Assistant Professor Obstetrics and Gynaecology, Chandka Medical College Hospital Larkana ${ }^{2}$,Associate Professor Paediatric \\ Medicine, Chandka Medical College Hospital Larkana, ${ }^{3}$ Assistant Professor in Dept of Pathology (Prof), Resident obgyn unit I, \\ Chandka Medical College Hospital Larkana
}

\begin{abstract}
Aims: Teenage pregnancy has globally recognized as high risk pregnancy. Under grown pelvic bones at delivery pose greater risk of obstructed labour in such young girls resulting in poor feto-maternal outcome. Objective of this study was to determine the frequency of obstructed labor in teenage pregnancy and to know fetomaternal outcome.

Methods: This Cross Sectional Observational study was conducted at department of Obstetrics and Gynecology unit I and II, Shaikh Zyed Women Hospital Chandka Medical College, Shaheed Mohtarma Benazir Bhutto Medical University Larkana Sindh Pakistan from 1st January 2010 to 31st December 2010. 468 women admitted with obstructed labour of all age groups, out of these which 257 patients were teenage mothers. Patients selected after fulfilling selection criteria. Obstructed labour in teenage patients wasdiagnosed on the basis of history of prolonged labour and clinical presentation. Demographical characteristics noted. Mode of the delivery and fetomaternal outcome was observed. Statistical analysis was performed using SPSS. 12 version.
\end{abstract}

Results: Total deliveries in both units during study period were 9000. Among them 468(5.2\%) patients found to have obstructed labour. Out of these $257(2.85 \%$ of total) patients were teenagers.. $82 \%$ (210) teengers were non booked and admitted in emergency while only $18 \%(47)$ came through OPD having a single visit. Mean age was $16 \pm 2$ years and parity was $2 \pm 1$. 5 . Mode of delivery was LSCS in $84 \%$ (214), assisted vaginal delivery in $12 \%$ (32) and $4 \%(11)$ had spontaneous delivery with episiotomy. Cephalopelvic disproportion remained the commonest reason of obstruction (66\%). $1.94 \%$ (5) of patients died of septicemia .PPH seen in $41 \%(105), 1.1 \%$ (3) had scar dehiscence due to prolonged trial by untrained birth attendant.1.94\% (5) patients developed vesicovaginal fistula later on. Perinatal mortality was around $54.6 \%$ (142) while $44.75 \%$ (115) babies born alive.

Conclusions: Adolescent pregnant women not only face pregnancy related problem but also they are prone to have obstructed labour due to their developing pelvic bones. Obstructed labour is one of the most common and preventable causes of maternal and perinatal deaths and disabilities.

Keywords: Maternal mortality, obstructed labour, perinatal mortality, teenage pregnancy

\section{INTRODUCTION}

Teenage pregnancy is defined by World Health Organization (WHO) as a pregnancy occurring in girls aged $10-19$ years. ${ }^{1}$ Approximately $10 \%$ of all births occur in teenage mother worldwide. ${ }^{2}$ Whether its maternal age or parity and even social class or ehinic group of mother, all these socio-

\section{CORRESPONDENCE}

Dr. Shahida Shaikh

Banglow no:9 Type III New Staff Colony

Chandka Medical college Larkana

Phone:92-333-7543377

Email: shahida.doctor@gmail.com demographic factors definitely persuade maternal health and childbearing. ${ }^{2}$ Due to the old customs and certain taboos, South Asian countries have higher proportions of teenage pregnancies, as early marriage is common among them and there is a social expectation to have a child soon. ${ }^{3}$ This period of teenage or adolescent females 
is always taken as the intermediary stage of physical and mental health development from innocent childhood to procreating adulthood, thus the pregnancies transpiring in teenage girls are usually classified to carry high risk in comparison to those in adult females. ${ }^{4}$ Gynecological nastiness and the development with maternal compromised nutritional status have been accredited to adverse pregnancy outcome. ${ }^{5}$ Certain problems like preterm labour, pregnancy induced hypertension, sexually transmitted diseases, anemia and low birth weight are strappingly implicated with adolescent pregnancy. ${ }^{6}$ Other complications like intra partum eclampsia, abnormally prolonged or obstructed labour and postpartum hemorrhage are more common in the age before 20 years. $^{7}$ Neonates have been seen suffering from morbidities like birth asphyxia and subsequent cerebral palsy, low APGAR score, RDS and also neonatal hyerbilirubinia. ${ }^{8}$ Teenage mothers are physically under developed. ${ }^{7}$ Parents consider their girl mature at menarche, but a young women's pelvis still takes more time to grow, therefore pregnancy and birth at a young age results in serious risks for both mother and child. ${ }^{7}$ In developing and poor societies where there is high frequency of teenage pregnancy and usually labour takes place outside the hospitals either conducted by some relative, old age untrained midwives results in obstructed labour and consequently significant maternal morbidity and mortality occurs. ${ }^{9}$ According to one study that has been done in Bangladesh on the complications of adolescent pregnancy, more than $50 \%$ teenagers suffer pregnancy obstacles; about $98 \%$ adolescent had different complications like hypertensive disorders, labour dystocia, postpartum hemorrhage and delay in delivery of placenta. ${ }^{7}$

The prevalence of teenage pregnancy is still high world wide. Lot of research has been done regarding the risk factors complications and out come of teenage pregnancy, but study specifically focused on teenage and obstructed labour is quite scarce in our country. Teenage pregnancy and obstructed labour are both getting very common so the aim of this study is to observe specifically the frequency of obstructed labour in teenage mothers as it mostly results in serious maternal and fetal complications.

\section{METHODS}

This cross sectional study was conducted from $1^{\text {st }}$ January 2010 to $31^{\text {st }}$ December 2010. It was carried out in the department of Obstetrics and Gynecology Unit I and II Sheikh Zyed Women Hospital,Chandka Medical College Shaheed Mohtarma Benazir Bhutto Medical University Larkana Sindh Pakistan (200 bedded hospital) after approval from institutional ethical committee. A total 257 teenage woman included in study who fulfilled the following selection criteria recruited for study. Sample size calculated according to prevalence of obstructed labour in teenage women. ${ }^{7}$

\section{INCLUSION CRITERIA}

1. Age between $10-19$

2. Gestational age from 37 weeks onward

3. Singleton pregnancy

\section{EXCLUSION CRITERIA}

1. Age 20 years and above

2. Patients with preterm labour and premature rupture of membranes

3. Mother with major illness existing from pre-pregnancy state

4. Patients having history of substance abuse

Study protocol was explained and informed written consent taken. Gestational age was calculated on earlier dating ultrasound where available. Obstructed labour was diagnosed on the basis of history and clinical examination. Blood pressure, temperature and pulse monitored at admission and then frequentlyDuartion) according to patients condition. All patients were catheterized at admission. Baseline investigations like complete blood picture, blood sugar and urine DR and specific labs like urea, creatinine and serum electrolytes also sent. HVS was sent for culture and sensitivity. Findings favoring obstructed labour obtained on examination were recorded on pre-designed proforma. Mode of delivery, and fetal outcome observed. Maternal complications during labour till discharge from hospital noted and also on follow up visits till 6 weeks. Data was analyzed with help of Statistical Package for Social Sciences (SPSS version. 12). Mean and standard deviation was computed for quantitative variable like frequency, age, gestational age, parity and perinatal outcome.

\section{RESULTS}

In the year 2010 from $1^{\text {st }}$ January to $31^{\text {st }}$ December total number of deliveries were 9000 . A total of 468 (5.2\%) patients were diagnosed having obstructed labor and out of them 257 ( $2.85 \%$ of total) were teenage patients . Frequency increased after the month of August because of floods in upper Sindh. The most of the patients i.e $82 \%$ (210) were un booked came in emergency and only $18 \%$ (47) gave history of single erratic visit to local GP. Mean age was $16 \pm 2$ years and frequency of different age groups are mentioned in table 1 . Mean parity was $2 \pm 1.5$ and

about $73.9 \%$ (190) were primigravidas and remaining were in their subsequent pregnancies. All patients gave history of trial for more than six hours either by midwife or nearby doctor. 33\% (85) patients came in severe obstruction with distended bladder and huge vulval odema.Cephalopelvic disproportion was cause of obstruction found in $66 \%$ (169) patients followed by occipitoposterior position in $9.76 \%(25)$, abnormal presentation(transverse lie) in $8.8 \%$ (22), deep transverse arrest in $7.3 \%(19)$ breech presentation in $4 \%(11)$ and fetal anomaly(mainly hydrocephalus) 
in another $4 \%(11)$ patients. About $84 \%$ (214) patients delivered through caesarean section, $12 \%(32)$ had had assisted vaginal delivery and spontaneous vaginal delivery with episiotomy conducted in $4 \%(11)$ women. Fetal out come is shown in table 2. Post partum hemorrhage was the commonest complication seen in $41 \%$ (105) patients .We lost 5 (1.94\%) mothers who died of septicemia and another 23\%(59)developed puerperal pyrexia. About 1.1\% (3) patients had scar dehiscence found when operated. $1.94 \%$ (5) patients developed vesicovaginal fistula when they were being discharged home although catheterized. Perinatal mortality remained around 55\% (142) at seven days post delivery

\section{Table 1.patients variables}

\begin{tabular}{lll}
\hline Variable & Number & Percentage \\
\hline Age & & \\
10-14years & 44 & $17.12 \%$ \\
15-19years & 213 & $82.87 \%$ \\
Parity & & \\
Primigravidae & 190 & $73.9 \%$ \\
2-3 & 67 & $26.0 \%$ \\
Antenatal visits & & \\
Single visit & 47 & $18 \%$ \\
Un-booked & 210 & $82 \%$ \\
\hline
\end{tabular}

Table2.fetal outcome

\begin{tabular}{lll}
\hline Outcome & number & percentage \\
\hline Alive & 115 & $44.74 \%$ \\
Still birth & & \\
Fresh andMacerated & 89 & $34.6 \%$ \\
Neonatal death & 53 & $20.6 \%$ \\
\hline
\end{tabular}

\section{DISCUSSION}

Pakistan is a geographical entity mired in primitive traditions and customs, consanguineous and early age marriages giving rise adolescent pregnancy. Subsequently these tender age women suffer from many pregnancy and labour complications. ${ }^{10}$ Teenage pregnant girls have different circumstances and reproductive needs and is the reason why the labour related complications like obstructed labour affects almost South Asian and African countries and is obsolete from developed world. ${ }^{11}$

At our hospital, we found the percentage of 5.8 of all obstetrical admissions were of obstructed labour and among them teenage girls comprised more than half of those women with obstructed labour (54.9\%) and $2.85 \%$ of total admissions which is near to global figureswhich is $3-6 \% .{ }^{12}$ This numberis also consistent with the study conducted in Nigeria although the prevalence of obstructed labour in that hospital was about $0.8 \%$ but Omole-ohansi states that highest frequency was seen in teenage girls. ${ }^{9}$ Another community based study in Sudan observed that $59 \%$ teenage girls out of his 52 patients reported with obstructed labour complications. ${ }^{13}$ Girls belonging to lower socioeconomic group are usually having malnutrition and before they achieve their maximum growth potential they get married so they start their childbearing with inadequate pelvis resulting in obstructed labour. ${ }^{14}$ Teen age primigravidas are worst sufferers of obstructed labour and they amounted up to $73.9 \%$ in this study and is endorsed by other studies..$^{8,9,14}$ Obstetrical complications can be avoided when proper antenatal visits are emphasized and risk factor evaluation is done but adolescents are more communally restricted than adults from seeking well-timed and suitable prenatal care, ${ }^{15}$ same is the condition applied to our study where we had $82 \%$ unbooked patients and only $18 \%$ admitted for taking sporadic single visit in dire emergency. This problem is also appreciated by other authors in their respective studies. 1,16,17 Cephalopelvic disproportion has been identified as the main cause of obstructed labour in these young women world widely due to under developed pelvis in teenage girls as corroborated with study by Indian authors as well , in which he found the main problem of Cephalopelvic disproportion in a comparative study of teenage with adult women. ${ }^{18}$ Biological, social and familial implications make the teenage women vulnerable to many child birth related problems and usually they are taken to hospitals late when they have abnormally prolonged or obstructed labour. This is the reason where these poor women are exposed to higher cesarean and instrumental deliveries as early intervention to deliver baby becomes necessary when they arrive in hospital. Current study found the highest rate of cesarean and instrumental vaginal delivery and just $4 \%$ of women delivered naturally and these findings are consistently supported by many studies from other countries ${ }^{8,9,19,20}$ and even a report by WHO cited the rate of cesarean section in $90 \%$ of obstructed labour and instrumental delivery in remaining $10 \%$ of patients. ${ }^{21}$ Adolescent girls not only suffer due to pregnancy itself but also they face the fear of death and disability due obstructed labour common in them as described in results of our study which shows five patients (1.94\%) died due to septicemia, 2 paitents had scar dehiscence and another $41 \%(105)$ patients had developed mild to moderate post partum hemorrhage $23 \%$ had puerperal pyrexia and 5(1.94\%) patients had already developed socially unacceptable morbidity like vesicovaginal fistula. Universally acknowledged truth is that $13 \%$ and $15 \%$ of maternal global burden of deaths and disease respectively is tolerated by these young ladies, ${ }^{15}$ while obstructed labour alone only has remained the cause of death in $8 \%$ of maternal deaths which is higher from our study. ${ }^{12}$ Along with maternal mortality many studies are of opinion of increased perinatal mortality and at our setup perinatal 
mortality remained around $55 \%$ comprising of not only still birth but early neonatal deaths too and obviously high as usually these patients report late after having long trial and is related to studies done by Mukhpapadhyay and Lewis ${ }^{22,23}$ who showed adverse perinatal outcome in teenage primigravid mothers significantly high in comparison to elderly primigravidaes. This adverse fetal outcome is seen in overall teenage girls whose babies are already at risk due to their age related morbidities and superadded to it is teenage girls coming with obstructed labour where perinatal mortality has been reported as high as in Nigeria ${ }^{9}$ up to $52.9 \%$ and one study done in Pakistan stated PMR of $31 \%$ where they had to relieve mother with destructive operations along with cesarean section. ${ }^{24}$

Our study supports the opinion that teenage pregnancy increases the chances of adverse pregnancy outcomes. Poverty, illiteracy and adherence to old customs are important indicators of early age marriage, early child bearing and subsequently undesirable end results. Reducing adolescent pregnancies and offering enhanced prenatal emergency obstetric care to pregnant adolescents can result in avoidance of such catastrophic fetomaternal complications

\section{CONCLUSION}

Promoting girls education can help preventing adolescent marriage in every society. Education can bring the developmental changes in girls influencing them to improve their quality of life, above all this will make them understand of human rights and their own rights. Teenage pregnancy poses many problems including the gross nutritional deficiencies which can result in obstructed labour. Early and adequate prenatal care should be tailored to the medical, social, nutritional, and educational needs of the adolescents and should include baby care training as well. Identification of prolonged labour and early referral to tertiary care hospital can save many lives.

\section{REFERENCES}

1. Omar K, Hasim S, Muhammad NA, Jaffar A, Hashim SM, Siraj HH. Adolescent pregnancy outcome and risk factors in Malaysia, Int Journal of Gyneacology and Obstetrics. 2010;111(3):220-3.

2. Naz S, Paeveen R, Bhatti A, Baloch R, Hanif M. Teenage pregnancy (Are teenager a risk group?). Medical Channel of Pakistan Gyneacology and Obstetrics. 2010;140-3.

3. Raj AD, Rabi B, Amudha P, Edwin R VT, Glyn C. Factors associated with teenage pregnancy in south Asia A systemic review. Health science journal. 2010;4(1):3-14.

4. Kovavisarach E, Chairaj S, Tosang K, A savapiriyanont S, Chotigeat U. Outcome of teenage pregnancy in Rajavinthi hospital. J Med association Thai. 2010;93(1):1-8.

5. Khashan AS, Baker NP, Kenny LC. Preterm birth and reduced birth weight in first and second teenage pregnancies a register based cohort study, Biomed central pregnancy and childbirth. 2010;36(10):10-36

6. Banerjee B et all. Teenage pregnancy: A socially inflicted health hazard. Ind J of community medicine. 2009;34(3):227-31.
7. Rahman MM, Hasan M, Akter S, Sultana P. Adolescent pregnancy complication and wastage in Bangladesh. J Nep peadtr Soc. 2010;30(3):146-53.

8. Kumar A, Singh T, Basu S, Pandey S, Bhargava V. Outcome of teenage pregnancy. Ind J of pediatrics .2007;74(10):927-31.

9. Omole-ohansi A, Ashimi O. Obstructed labour-A six year review in Aminn kano teaching hospital, Kano, Nigeria. Nigerian medical practitioner. 2007;51(4):59-63.

10. Lane, S. "Stealing Innocence: Child Marriage and Gender Inequality in Pakistan", Plan Finland \&Abo Akademi University, Finland.2011;1-44 www.ykliitto.fi/.../seminar_on_child_marriage_and_gender_ inequal...

11. Adhikari S, Dasgupta M. Management of obstructed labour: a retrospective study. J Obstet Gynecol India. 2005;55(1):48-51.

12. Kongnyuy EJ, Mlava G, Broek VDN. Establishing standards for obstructed labour in a low-income country Rural and Remote Health (online ). 2008;1022( 8):1-10.

13. Mohamed E Y et al. Contributing factors of vesico-vaginal fistula(VVF)among patients in Dr.Abbo 's National Fistula \& Urogynaecology Center Khartoom Sudan. Sudanese journal of public health. 2009;4(2):259-64.

14. Konje JC, Ladipo OA. Nutrition and obstructed labour. Am j clin Nutri. 2000;72(1):291S-97S.

15. Khan N. World Health Organization. Adolescent pregnancyunmet needs and undone deeds: a review of the literature and programmes. Geneva, Switzerland: WHO Press. 2007;1-112.

16. Ebeigbe N P,Gharoro E P.Obstetrical complications,intervention rates and maternofetal outcome in teenage nullipara in Benin city,Nigeria.Rop Doct. 2007;37:79-83.

17. Watcharaseranee $N$, Pinchantra $P$, Piyaman S.The incidence and complications of teenage pregnancy at Chonuburi hospital. J Med Assoc Thai .2006;89(Suppl 4):S118-23.

18. Chahande M S, Jadhao A R, Wadhva S K, Ughade S. Study of Some Epidemiological Factors in Teenage Pregnancy - Hospital Based Case Comparison Study. Indian Journal of Community Medicine. 2002;27(3):7-9

19. Canbaz S,Sunter A T,Cetinoglu C E,Peksin Y.Obstetric outcomes of adolescent pregnancies in Turkey. Advance in Therapy. 2005:22(6):636-41.

20. Al-Rahmahi M,Saleh S.Out come of adolescent pregnancy at a university hospital in Jordan. Arch Gnnecol Obstet. 2006;237(4):207-10

21. Dolea C, Abouzahr C. Global burden of obstructed labour in theyear 2000. Geneva: Evidence and Information for Policy. World Health Organisation. 2003;1-7.

22. Mukhopadhyay P,Chaudhuri,RN, PaulB. Hospital-based perinatal outcomes and complications in teenage pregnancy in India. Health Popul Nutr. 2010;28(5):494-500.

23. Lewis LN,Hickey $m$, Doherty DA,Skinner SR. How do pregnancy outcomes differ in teenage mothers? A Western Australian study. Med J Aust. 2009;190(10):537-41

24. Memon S, Qazi R A,Pushpa,Khushk A. Patterns of Obstructed labour at a public sector university hospital of Sindh,Pakistan. 2009;8(1):60-4. 